\title{
Diacronie
}

Studi di Storia Contemporanea

$\mathrm{N}^{\circ} 36,4 \mid 2018$

Viaggi e turismo nell'Europa del Novecento

\section{Viaggiare per fede. Il pellegrinaggio alla Mecca e la politica estera jugoslava (1949-1961)}

\section{Mario Giulio Salzano}

\section{Q OpenEdition}

\section{Edizione digitale}

URL: https://journals.openedition.org/diacronie/10338

DOI: 10.4000/diacronie. 10338

ISSN: 2038-0925

\section{Editore}

Association culturelle Diacronie

\section{Notizia bibliografica digitale}

Mario Giulio Salzano, «Viaggiare per fede. II pellegrinaggio alla Mecca e la politica estera jugoslava (1949-1961)», Diacronie [Online], № 36, 4 | 2018, documento 9, online dal 29 décembre 2018, consultato il 17 février 2022. URL: http://journals.openedition.org/diacronie/10338 ; DOI: https:// doi.org/10.4000/diacronie.10338 


\title{
Diacronie
}

Studi di Storia Contemporanea

$36,4 / 2018$

Viaggi e turismo nell'Europa del Novecento

\section{Viaggiare per fede. Il pellegrinaggio alla Mecca e la politica estera jugoslava (1949-1961)}

\author{
Mario Giulio SALZANO
}

Per citare questo articolo:

SALZANO, Mario Giulio, «Viaggiare per fede. Il pellegrinaggio alla Mecca e la politica estera jugoslava (1949-1961)», Diacronie. Studi di Storia Contemporanea :Viaggi e turismo nell'Europa del Novecento, 36, 4/2018, 29/12/2018,

URL: <http://www.studistorici.com/2018/12/29/salzano_numero_36/ >

Diacronie Studi di Storia Contemporanea $\rightarrow$ http://www.diacronie.it

Rivista storica online. Uscita trimestrale.

redazione.diacronie@hotmail.it

Comitato di direzione: Naor Ben-Yehoyada - João Fábio Bertonha - Christopher Denis-Delacour - Maximiliano Fuentes Codera Anders Granås Kjøstvedt - John Paul Newman - Deborah Paci - Niccolò Pianciola - Spyridon Ploumidis - Wilko Graf Von Hardenberg

Comitato di redazione: Jacopo Bassi - Luca Bufarale - Gianluca Canè - Luca G. Manenti - Fausto Pietrancosta - Alessandro Salvador - Matteo Tomasoni - Luca Zuccolo

Diritti: gli articoli di Diacronie. Studi di Storia Contemporanea sono pubblicati sotto licenza Creative Commons 3.0. Possono essere riprodotti e modificati a patto di indicare eventuali modifiche dei contenuti, di riconoscere la paternità dell'opera e di condividerla allo stesso modo. La citazione di estratti è comunque sempre autorizzata, nei limiti previsti dalla legge. 


\title{
9/ Viaggiare per fede. Il pellegrinaggio alla Mecca e la politica estera jugoslava (1949-1961)
}

\author{
Mario Giulio SALZANO
}

In Jugoslavia, nei primi anni del secondo dopoguerra, l'organizzazione dell'annuale pellegrinaggio alla Mecca (hadž) era vincolata dalle rigide direttive del Segretariato statale degli Affari Interni (DSUP, Državni Sekretarijat Unutrašnjih Poslova). Tra il 1949 e il 1961, prima che iniziasse ad assumere le connotazioni di un fenomeno di massa, la partecipazione all hadž fu rigorosamente limitata a un ristretto numero di funzionari religiosi "fidati". L'atteggiamento delle autorità fu apparentemente controverso. Nonostante le severe restrizioni imposte sul numero dei partecipanti, il viaggio alla Mecca fu anzitutto l'occasione per poter veicolare il "nuovo volto" del socialismo jugoslavo nei Paesi arabi del Mediterraneo orientale, negli stessi anni in cui si consumava la prima grave crisi tra il Partito comunista dell'Unione Sovietica e il Partito comunista jugoslavo (1948-1955). L'organizzazione dell'hadž fu in larga parte condizionata dai rapporti diplomatici jugoslavi con i Paesi del Medio Oriente. La mediazione dei funzionari musulmani bosniaci nei rapporti diplomatici con le istituzioni politiche e religiose dei Paesi arabi di tradizione islamica, è testimoniata dalle relazioni della Commissione per gli Affari religiosi (KZVP, Komisija za Vjerska Pitanja) e della Comunità religiosa islamica (IVZ, Islamska Vjerska Zajednica). L'atteggiamento delle autorità governative jugoslave riguardo il pellegrinaggio alla Mecca, nella sua duplice dimensione di fenomeno religioso e politico, è un interessante punto di partenza per aprire nuove prospettive di indagine sui rapporti tra il Partito comunista jugoslavo poi Lega dei comunisti jugoslavi (Komunistička Partija Jugoslavije; dal 1952 Savez Komunista Jugoslavije) e la componente musulmana di Bosnia-Erzegovina.

La Repubblica Popolare Federativa di Jugoslavia ${ }^{1}$ nacque come entità plurinazionale dall'unione di sei repubbliche e cinque nazioni, fondata sull'assunto ideologico che il Partito comunista sintetizzò nella formula bratstvo i jedinstvo (fratellanza e unità). L'impalcatura della dottrina politica socialista, posta alla base delle relazioni tra i popoli e le repubbliche della Federazione jugoslava, iniziò a vacillare già a partire dalla prima metà degli anni Sessanta, sotto il peso crescente delle mai sopite tensioni tra i principali gruppi nazionali. In Bosnia-Erzegovina la

${ }^{1}$ Federativna Narodna Republika Jugoslavije (dal 1963 Socijalistička Federativna Republika Jugoslavije). 
declinazione più evidente di questo fenomeno si manifestò alla vigilia degli anni Settanta, all'apice del processo di affermazione nazionale della componente musulmana. Di fatto, attraverso un graduale percorso di legittimazione istituzionale, sancito da una serie di dichiarazioni e atti ufficiali resi noti tra il 1968 e il 1974, la componente musulmano-bosniaca fu riconosciuta quale sesta nazione costituente della Repubblica Socialista Federativa di Jugoslavia. $\mathrm{Fu}$ l'esito di un moderno processo di nation-building, promosso dal Comitato Centrale della Lega dei comunisti di Bosnia-Erzegovina ${ }^{2}$, coadiuvato dagli intellettuali bosniaci vicini al Partito e sostenuto, in ambito federale, dalla Lega dei comunisti jugoslavi ${ }^{3}$.

L'evoluzione dei rapporti tra il Partito comunista e la Comunità religiosa islamica è stata recentemente oggetto di studi che ne hanno evidenziato non solo le prevedibili criticità, ma anche gli elementi più rappresentativi delle fasi che hanno caratterizzato questa complessa ma pur stabile relazione che si è snodata, tra inevitabili difficoltà, nel corso del lungo dopoguerra jugoslavo. Alla prima fase, quella compresa tra il 1948 e il 1955, nota come "periodo dell'informbiro", ovvero dalla riorganizzazione dei vertici della Comunità religiosa islamica all'apice della crisi tra il KPJ e il $\mathrm{KPSS}^{5}$, seguì un momento di graduale distensione nei rapporti tra il Partito e la comunità musulmana ${ }^{6}$. Ciò emerse in particolar modo nel periodo compreso tra il 1955 e il 1961, anni che coincisero, come vedremo, con un'importante apertura della diplomazia jugoslava nei confronti dei paesi arabi di tradizione islamica, fautori della politica del non allineamento.

L'analisi dei rapporti tra le istituzioni dello Stato e la comunità religiosa islamica, che sono al centro delle riflessioni proposte nel presente lavoro, si è avvalsa principalmente dei rapporti della Commissione per gli Affari religiosi e del Comitato Centrale della Lega dei comunisti della BosniaErzegovina, e si è concentrata su uno specifico fenomeno della tradizione religiosa e culturale

\footnotetext{
${ }^{2}$ Centralni Komitet Saveza Komunista Bosne i Hercegovine.

3 Sulle vicende della questione nazionale musulmana del secondo dopoguerra, si rimanda ad alcuni dei principali contributi della recente storiografia sull'argomento: LUČĆĆ, Iva, Making the "Nation" Visible: Socialist Census Policy in Bosnia in the early 1970s, in BRUNNBAUER, Ulf, GRANDITS, Hannes (eds.), The Ambiguos nation, Case Studies from Southeastern Europe in the 20th Century, München, Oldenbourg Verlag, 2013, pp. 423448; LUČIĆ, Iva, «In the Service of the Nation: intellectuals' articulation of the Muslim national identity», in The Journal of Nationalism and Ethnicity, 40, 1/2012, pp. 23-44; Rasprave o nacionalnom identitetu Bošnjaka, Sarajevo, Institut za istoriju, 2009; BOUGAREL, Xavier, Survivre aux empires. Islam, identité nationale et allégeances politiques en Bosnie-Herzégovine, Paris, Karthala, 2015.

4 Si veda, tra gli altri: BEĆIROVIĆ, Denis, Islamska Zajednica u Bosni $i$ Hercegovini za vrijeme avnojevske Jugoslavije (1945-1953), Sarajevo, Institut za istoriju, 2012; SARAČ-RUJANAC, Dženita, Odnos vjerskog $i$ nacionalnog u identitetu Bošnjaka od 1980. do 1990. godine, Sarajevo, Institut za Istoriju, 2012; FILANDRA, Šaćir, KARIĆ, Enes, Bošnjačka ideja, Zagreb, Nakladni zavod Globus, 2002; RADIĆ, Radmila, «Islamska Verska Zajednica 1945-1970. godine», in Forum Bosnae, 32, 6/2005, pp. 99-134; JOVIĆ, Dejan, «Identitet Bošnjaka/Musliman», in Politčka Misao, L, 4/2013, pp. 132-159.

${ }^{5}$ Partito comunista jugoslavo (Komunistička Partija Jugoslavije o KPJ); Partito comunista dell'Unione Sovietica (Kommunističeskaja Partija Sovetskogo Sojuza o KPSS/KПCC).

${ }^{6}$ Questa fase fu contrassegnata da una spietata repressione interna nei confronti dei dissidenti politici e religiosi.
} 
islamica: il pellegrinaggio alla Mecca. Si tratta di una prassi che tra i musulmani bosniaci si è affermata sin dalle prime fasi dell'occupazione ottomana e rappresenta uno degli aspetti più evidenti del lungo processo di islamizzazione della regione. La tradizione del pellegrinaggio, nella sua duplice espressione, individuale e collettiva, è uno degli elementi costitutivi dell'identità religiosa islamica che assimila i musulmani bosniaci al resto della comunità dei credenti (umma). Nella Jugoslavia del dopoguerra, questo fenomeno costituì uno dei poli più complessi del rapporto tra le istituzioni e la comunità religiosa islamica.

L'hadž (al-Hajj o حَ) il pellegrinaggio, è uno dei cinque pilastri della religione islamica ${ }^{8}$. Il pellegrinaggio alla Mecca è «il culmine massimo della vita del fedele» ${ }^{9}$. La sua origine è probabilmente anteriore alla diffusione dell'islam. Le più antiche attestazioni riguardo il pellegrinaggio alla Mecca, in epoca islamica, sono le esortazioni e le prescrizioni raccolte nel Corano e in alcuni hadīth ${ }^{10}$. A differenza degli altri quattro fondamenti dell'islam, i rituali previsti per l'hadž si possono compiere solamente nei luoghi sacri della Mecca ${ }^{11}$. Ogni musulmano adulto, se sussistono le condizioni di salute e le possibilità economiche, deve compiere il pellegrinaggio alla Mecca almeno una volta nella vita, possibilmente durante il mese Dhü l-Hijja del calendario lunare islamico ${ }^{12}$. Il fedele che esprime l'intenzione (nīya) di intraprendere il pellegrinaggio, entra in una particolare condizione di sacralità. Nella tradizione bosniaca, questo momento coincide con l'ikrar-dova, un atto solenne in cui il musulmano conferma la sua intenzione dinanzi alla comunità dei fedeli; da quel momento egli assume lo status di aspirante hadžija (pellegrino) ${ }^{13}$. A

\footnotetext{
7 I lemmi tematici di origina araba o persiana, che individuano alcuni dei principali concetti trattati in questo saggio, mantengono la trascrizione in lingua bosniaca e sono scritti in corsivo. Negli altri casi, le parole di origine araba sono rappresentate in tondo nella trascrizione in caratteri latini, e in alcuni casi accompagnate dalla trascrizione nei caratteri dell'alfabeto arabo. Riguardo i plurali in lingua araba si è scelto, nella maggior parte dei casi, di lasciare le parole trascritte al singolare anche quando in italiano sono usate in un contesto plurale, per cui, ad esempio, si troverà «i miqat» al posto del plurale arabo mawaquit.

${ }^{8}$ I cinque pilastri della religione islamica (Arkān al-Islām), sono: la professione di fede (Shahādah); la preghiera (Șalāt); l'elemosina rituale (Zakāt); il digiuno del mese di Ramadan (Sawm); il pellegrinaggio alla Mecca (al-Hajj).

9 VERCELLIN, Giorgio, Istituzioni del mondo musulmano, Torino, Einaudi, 2002, p.6.

10 Si veda ad esempio la sūra denominata al-Hajj, Corano 22, 27: «Chiama le genti al pellegrinaggio: verranno a te a piedi e con cammelli slanciati, da ogni contrada...» cfr. Il Nobile Corano e la traduzione dei suoi significati in lingua italiana, Medina, Arabia Saudita, Complesso del Re Fahd per la stampa del Nobile Corano, (eg. 1435) 2013; VERCELLIN, Giorgio, op. cit., p. 58. Gli hadith sono "aneddoti (ma la parola araba serve anche a indicarne collettivamente il complesso) che riferiscono un fatto (fi'l) o un detto (qawl) o anche un silenzio inteso come tacito assenso (sukūt) risalenti al Profeta o talora ai suoi compagni, ricordi che non possono contraddire il Corano ma solo chiarirlo". La stessa radice trilittera del verbo (h-d-th Hahatha) traduce i verbi "raccontare", "narrare".

${ }^{11}$ HUKIĆ, Habdurahman, Kako ću obaviti Hadž, Sarajevo, Starjesinstvo Ilamske zajednice u SRBiH, 1968, p.17. ${ }^{12 B A U S A N I, ~ A l e s s a n d r o, ~ L ' I s l a m . ~ U n a ~ r e l i g i o n e, ~ u n ' e t i c a, ~ u n a ~ p r a s s i ~ p o l i t i c a, ~ M i l a n o, ~ G a r z a n t i, ~ 1999, ~ p p . ~ 55-61 ; ~}$ VERCELLIN, Giorgio, op. cit., p. 222. Il pellegrinaggio alla Mecca può essere compiuto in ogni periodo dell'anno. Se intrapreso al di fuori del mese di Dhü l-Hijja, è chiamato Umra, il "pellegrinaggio minore"; pur non essendo obbligatorio, segue prescrizioni pressoché identiche a quelle del "grande pellegrinaggio", cfr. Corano 2, 196.

13 «Prvi hodočasnici iz nove Jugoslavije», in Glasnik Vrhovnog islamskog starješinstva (d'ora in avanti: Glasnik
} 
Sarajevo, la moschea tradizionalmente deputata all'hadžijski namaz (l'invocazione del pellegrino) è stata per molto tempo la Vekilharčova hadžijska džamija situata nella mahala Alifakovic; da qui partivano per il loro lungo viaggio i pellegrini diretti alla Mecca, e qui transitavano al loro ritorno.

In Bosnia-Erzegovina, l'origine di questa pratica religiosa è successiva alla metà del XV secolo e la sua affermazione coincise, orientativamente, con l'inizio di un insediamento più stabile degli Ottomani nella regione $(1463 \mathrm{ca} .)^{14}$. Il primo viaggio alla Mecca compiuto da un musulmano bosniaco, di cui si ha notizia, è il pellegrinaggio di Sarač Mehmed, partito da Sarajevo nel $1557^{15}$. Le prime testimonianze dirette sono di epoca successiva: e sono le memorie di viaggio di Hadži Jusuf Muhamed di Livno (1615) e di Hadži Mustafa Muhlisije di Gornji Vakuf (1749) ${ }^{16}$. La tradizione del viaggio alla Mecca si sviluppò quindi nel corso degli anni, parallelamente al processo di islamizzazione della regione, fino a diventare una pratica cultuale molto diffusa anche tra la popolazione musulmana della Bosnia-Erzegovina.

Nella Jugoslavia del secondo dopoguerra, le attività relative all'organizzazione dell'hadž erano affidate formalmente al Vrhovno Islamsko Starješinstvo (il Consiglio superiore islamico), ma di fatto erano vincolate dalle rigide direttive delle autorità governative ${ }^{17}$. Tra il 1949 e il 1961, il numero degli aspiranti pellegrini che ottenne il permesso di partire per la Mecca fu estremamente ridotto, a causa delle restrizioni imposte dalla Segreteria di Stato per gli Affari Interni (DSUP) ${ }^{18}$. Si trattava di individui politicamente "fidati", perlopiù funzionari della Commissione per gli Affari religiosi e della Comunità religiosa islamica. I motivi di questo atteggiamento, da parte delle autorità jugoslave, non sono del tutto chiari, anche se, in parte, essi sono riconducibili al clima politico generale, spesso ostile nei confronti delle attività e delle manifestazioni religiose. Secondo alcuni autori, si tratterebbe di una selezione spontanea dovuta ai costi elevati del viaggio, ma se consideriamo il numero delle richieste da parte dei pellegrini respinte dalle autorità, questa giustificazione trova accoglienza solo in minima parte ${ }^{19}$.

VIS-a), I (XII), 1-3/1950, pp.52-53.

14 ŠABANOVIĆ, Hazim, Bosanski Pašaluk, Sarajevo, Svjetlost, 1982, pp. 38 et seq.

${ }_{15}$ BEČIROVIĆ, Denis, Islamska Zajednica u Bosni i Hercegovini za vrijeme avnojevske Jugoslavije, cit., 406, n. 674.

16 «Nekoliko starijih rukopisa o putovanju na hadž», in Glasnik VIS-a, III, 8-12/1952, p. 261. Hadži, posto dinanzi ad un nome, ha la funzione di titolo onorofico che identifica coloro che hanno compiuto l'hadž. In epoca socialista, l'elenco degli hadžija veniva pubblicato annualmente sulla rivista Glasnik Vis-a.

17 Il Vrhovno Islamsko Starješinstvo o VIS (Consiglio superiore islamico) è uno dei maggiori organi rappresentativi della Comunità religiosa islamica (Islamska Vjerska Zajednica o IVZ). L'IVZ è l'istituzione di riferimento per i musulmani della Bosnia-Erzegovina, del Sangiaccato, della Croazia, della Serbia, della Slovenia, dei musulmani bošnjaci fuori i confini nazionali e degli altri musulmani che si riconoscono nei suoi principi costitutivi.

${ }^{18}$ Državni Sekretarijat Unutrašnjih Poslova

19 NOVAKOVIĆ, Dragan, «Organizacija hadževa i problemi koji su pratili izvršavanje te vjerske obveze u Jugoslaviji od 1945. do 1991. godine», in Ćasopis za suvremenu povijest, 36, 2/2004, pp. 463-471, p. 464. 
Gli anni immediatamente successivi all'espulsione del Partito comunista jugoslavo dal Cominform (28 giugno 1948), furono caratterizzati da una intensa attività diplomatica nel tentativo di traghettare il Paese verso un nuovo sistema di alleanze internazionali. I risultati più evidenti della politica estera jugoslava giunsero tra il 1955 e il 1961. Nella ricerca di una possibile alternativa alla geopolitica bipolare delle due superpotenze, Stati Uniti e Unione Sovietica, gli interessi della diplomazia jugoslava si orientarono verso il nascente Movimento dei Paesi non allineati. Nello stesso periodo, la crisi politica scaturita dalle decisioni dell'Informbiro favorì una diffusa attività repressiva nei confronti dei dissidenti "stalinista", e dei rappresentanti delle istituzioni religiose che si erano mostrati particolarmente ostili all'indirizzo ideologico e politico del Partito comunista. In ambito internazionale, l'atteggiamento autoritario delle istituzioni jugoslave era stato più volte oggetto di svariate accuse provenienti proprio dal mondo arabo. Per il Partito comunista, l'hadž si presentò quindi come l'occasione per veicolare nei Paesi arabi di tradizione islamica una nuova immagine di tolleranza, seppur fittizia, nei confronti della comunità musulmana jugoslava. Questo è quanto sembra emergere dai resoconti di viaggio, dai rapporti diplomatici e dalle pubblicazioni apparse in quegli anni sulla rivista Glasnik Vis (La voce del Consiglio superiore islamico) ${ }^{20}$.

I primi cinque pellegrini musulmani della Jugoslavia socialista diretti alla Mecca partirono da Sarajevo l'8 settembre 1949. Si trattava di Ibrahim Fejić, reis-ul-ulema ${ }^{21}$, Murat Šećeragić, vice reisul-ulema, Hasan Ljubunčić, presidente della Commissione per gli Affari religiosi della Repubblica Popolare della Bosnia-Erzegovina; Šuajb Arslan di Skoplje, funzionario del Vakuf e Sinan Hasani, funzionario della provincia autonoma di Priština.

I cinque hadžija lasciarono la Jugoslavia dal porto di Spalato a bordo del piroscafo Zagreb; dopo giorni di navigazione lungo la rotta che si snoda tra le isole di Corfù, Creta e Cipro, raggiunsero il porto di Beirut il 17 settembre, e da qui proseguirono in aereo fino al Cairo. Nei dieci giorni trascorsi in Egitto, la delegazione fu ricevuta da numerosi esponenti delle istituzioni governative

${ }_{20}$ Il primo pellegrino a pubblicare un lungo e dettagliatissimo resoconto in Jugoslavia, nel secondo dopoguerra, fu Hasan Ljubunčić, presidente della Commissione popolare per gli Affari religiosi (Narodna Komisija za Vjerska Pitanje). I suoi numerosi contributi furono pubblicati periodicamente con il titolo «Put na Hadž» sulla rivista «Glasnik VIS-a» I (XIII), 4-7/1950; pp. 130-136; 11-12/1950, pp. 341-345; II (XIV), 13/1951, pp. 51-54, 4-6/1951, pp. 172-176, 7-9/1951, pp. 295-298, 10-12/1951, pp. 389-392; III (XV), 1-4/1952, pp. 68-73; 5-7/1952, pp. 157-166; 8-12/1952, pp. 162-272; IV (XVI), 1-4/1953,pp. 40-51, 5-7/1953, pp. 152-161. Si segnalano inoltre i contributi di SKOPLJAK, Asim, «Jedna grupa naših Hadžija otputovala u Meku», in Glasnik VIS- $a$, V (XVII), 4-6/1954, pp. 105-107, VI (XVIII) 5-7/1955, pp. 189-190; ŠEVA, Mustafa, «Ove godine iz Jugoslavije obavilo je Hadž 46 Hadžija», in Glasnik Vis-a, IX (XXI), 9-12/1958, pp. 537-538; ŠEVA, Mustafa, "Jugoslavenske Hadžije na hodočašću», in Glasnik Vis-a, XII (XXIV), 7-9/1961, pp. 288-308; Uredinstvo 'Glasnika', «Naše Ovogodišnje Hadžije», VII (XIX), 10-12/1956, pp. 413, VIII (XX),10-12/1957, pp. 499; «Izvještaj o Jugoslovenskim hodočasnicima na Hadž 1959. Godine», X (XXIII), 10-12/1959, pp. 320-321; «Naše Hadžije u 1960. Godini», XI (XXIII), 10-12/1960, pp. 513-516; «Odlazak naših Hadžija u Mekkei Mukerremu», XXIX, 3-4/1960,pp. 158-159.

21 "Capo degli ulema" (ovvero capo dei sapienti, dei giureconsulti). È la più alta carica religiosa della Comunità islamica in Bosnia-Erzegovina. La sua istituzione risale al 17 ottobre 1882. 
e religiose. Il 21 settembre i pellegrini jugoslavi incontrarono il rettore dell'Università Al Azhar, una tra le più autorevoli e prestigiose istituzioni islamiche di tradizione sunnita nel Medio Oriente. Durante i colloqui, il rettore espresse la sua preoccupazione riguardo la chiusura dei tribunali sciaraitici, i processi ai religiosi musulmani e i mancati sussidi agli studenti jugoslavi al $\mathrm{Cairo}^{22}$. «A tutte le questioni la delegazione rispose difendendo la politica ufficiale della Jugoslavia» ${ }^{23}$. L'inviato al Cairo, Miloš Moskovljević, in un rapporto per il governo jugoslavo, scrisse:

L'idea di inviare un gruppo di nostri musulmani in pellegrinaggio è molto buona [...] A causa della propaganda contro lo Stato di un residuo gruppo di monarchici cetnico-ustascia, qui, dopo la guerra sono state diffuse informazioni inverosimili sul nostro Paese, ma il nostro lavoro di propaganda sembra mal organizzato e mal condotto, tanto da non avere alcun effetto [...] Bisogna considerare che in Egitto e negli altri paesi musulmani la fede gioca ancora un grosso ruolo nella vita dello Stato e ha una grande influenza sulle masse popolari ${ }^{24}$.

La presenza degli hadžija jugoslavi in Egitto si rivelò comunque provvidenziale:

Gli hadžija giungono nel momento giusto. Il loro arrivo e la loro partenza per il pellegrinaggio, la visita al rettore di Al Azhar, le preghiere alla moschea e le interviste ai giornalisti, tutto è stato diffuso nel mondo arabo [...] e ciò favorisce una buona disposizione nei confronti del nostro Paese ${ }^{25}$.

Prima di lasciare l'Egitto, gli hadžija adottarono una serie di prescrizioni rituali (ihram), che consistevano, allora come oggi, essenzialmente nell'osservanza di determinati comportamenti per preservare la "purezza" spirituale e corporale che si richiede al pellegrino prima di entrare in

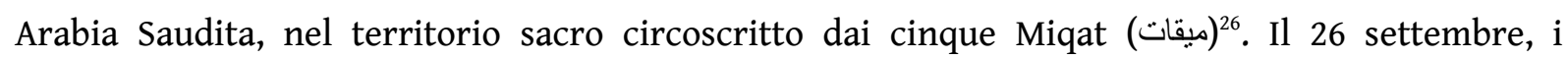

${ }^{22}$ BEČIROVIĆ, Denis, Islamska Zajednica u Bosni i Hercegovini, cit., p. 250; DURMIŠEVIĆ, Enes, «Prestanak važenja šerijatskog prava kao pozitivnog prava 1945. godine u Bosni i Hercegovini», in Glasnik Rijaseta Islamske Zajednice u Bosni i Hercegovini, LXIX, 11-12/2007, pp. 1055-1072. In Bosnia-Erzegovina i tribunali sciaraitici furono soppressi definitivamente con un'apposita legge pubblicata il 6 marzo 1946 sulla Gazzetta Ufficiale della Repubblica popolare della Bosnia-Erzegovina.

23 BEČIROVIĆ, Denis, Islamska Zajednica u Bosni i Hercegovini, cit., p. 407.

24 RADIĆ, Radmila, «Islamska Verska Zajednica u službi jugoslovenske spoljne politike», in Tokovi Istorije. Institut za noviju istoriju Srbije, 3-4/2000, pp. 39-49, p.40.

${ }^{25}$ Ibidem.

${ }^{26}$ I cinque miqat sono sostanzialmente punti geografici che delimitano una regione molto estesa che comprende diverse città e paesi attorno alla Mecca. Ai pellegrini che arrivano in aereo fino a Gedda, pur non essendo la città sede di un miqat, è richiesto, secondo una prassi consolidata, lo stato di ihram. L'ihram, oltre a rappresentare una serie di atti rituali, è anche il nome di una veste cerimoniale di coloro bianco che i pellegrini indossano in questa particolare fase del viaggio, proprio per attestare lo stato di "purezza". Altre sei "porte" delimitano i confini sacri della Mecca; si tratta di un territorio (Haram) in cui i pellegrini, trovandosi in stato di ihram, devono astenersi dal compiere alcune azioni, quali cacciare animali selvaggi, 
pellegrini, partiti dall'aereoporto del Cairo, raggiunsero la citta araba di Gedda, sulla costa orientale del Mar Rosso. Alle 11 di sera gli hadžija jugoslavi lasciarono la città portuale saudita e giunsero alla Mecca dopo due ore di viaggio in macchina. Qui furono accolti da una guida (delil) e, nonostante l'ora tarda, si recarono nella Moschea Sacra Al-Masjid al-Ḥarām (المدجد الحرام) al cui interno si trova la $\mathrm{Ka} b a$ (كعبة). I rituali religiosi più importanti, che gli hadžija jugoslavi avrebbero compiuto a partire dalla mattina successiva, si sarebbero svolti tra la Ka ba, Arafat, Muzdalifah e Mina ${ }^{27}$. Nei suoi resoconti di viaggio, Ljubunčić trascrisse minuziosamente i rituali compiuti nei diversi luoghi di culto e le impressioni riguardo i fedeli incontrati durante il lungo viaggio. Come nella tradizione della letteratura odeporica di epoca moderna, Ljubunčić si soffermò sulle descrizioni dei luoghi, delle persone, del cibo e della tipologia di alloggi riservati al viaggiatore, senza risparmiare, in alcuni casi, critiche severe. Ljubunčić fu molto colpito, ad esempio, dalla sala d'aspetto dell'aeroporto di Gedda, che nei suoi scritti definì più volte "primitiva". Ben presto, però, nel suo racconto, il disappunto iniziale lasciò spazio alla meraviglia che colse i viaggiatori al loro arrivo nei luoghi sacri della Mecca.

Il 14 ottobre, dopo aver compiuto tutti i rituali prescritti per il pellegrinaggio, la delegazione jugoslava ripartì in aereo da Gedda diretta in Libano. A Beirut gli hadžija furono trattenuti cinque giorni a causa di una "quarantena" che i medici dell'aeroporto imposero a tutti i pellegrini provenienti dalla Mecca. Durante il soggiorno nella capitale libanese i cinque hadžija si recarono per una breve visita nella città siriana di Damasco. Tornati a Beirut, il 22 ottobre ripartirono per raggiungere la città siriana di Aleppo. Il successo "diplomatico" dell'improvvisata delegazione jugoslava si riscontra nella nota inviata il 28 ottobre 1949, dall'incaricato degli Affari della FNRJ a Damasco, Lazar Lilić, al Ministero degli Affari interni jugoslavo, per riferire che l'arrivo degli hadžija «cade in un momento propizio e agisce favorevolmente presso l'opinione pubblica araba riguardo la questione del voto per la Jugoslavia nelle Nazioni Unite per la scelta del Consiglio di Sicurezza. La Siria ha avanzato la proposta alla Lega araba di votare in blocco per la candidatura della Jugoslavia» ${ }^{28}$. Il mattino successivo, gli hadžija salirono sul treno partito da Baghdad, diretto ad Ankara e poi a Istanbul. In Turchia, la delegazione fu accolta dai rappresentanti della diaspora bosniaca e dalle autorità locali. Dopo qualche giorno di riposo, gli hadžija jugoslavi ripartirono con l'Orient Express diretti a Belgrado.

Il pellegrinaggio alla Mecca fu l'occasione per respingere pubblicamente le accuse mosse in ambito internazionale nei confronti del regime comunista riguardo le presunte violazioni della libertà di culto. $\mathrm{Fu}$ lo stesso Ljubunčić che a tal proposito scrisse nelle sue memorie: «la calunnia e

danneggiare le piante, pascolare animali, portare armi, compiere atti sessuali o comunque trasgredire qualsiasi prescrizione relativa a determinati comportamenti.

27 BAUSANI, Alessandro, op. cit., p. 60 «Non tutte le cerimonie dell'ḥaǵǵ sono strictu sensu obbligatorie («colonne dell'ḥaǵǵ» sono l'Ihrrām, il vuquf di 'Arafat, il tawaf e il sa 'y)».

${ }^{28}$ RADIĆ, Radmila, «Islamska verska zajednica u službi jugoslovenske spoljne politike», cit., p. 41. 
le bugie che hanno diffuso i nemici, sostenendo che la libertà religiosa in Jugoslavia non esiste, sono state smascherate davanti a tutto il mondo ${ }^{29}$. Ma, questa e altre simili affermazioni non sembrano trovare pieno riscontro nella realtà giudiziaria di quegli anni. La costituzione della FNRJ del 31 gennaio 1946 aveva posto una chiara delimitazione tra la dimensione religiosa e quella pubblica $^{30}$. Nei fatti, gli apparati dello Stato, attraverso i servizi per la sicurezza interna (UDB), esercitavano un controllo vigile, costante e molto accurato sulle attività cultuali e sui funzionari religiosi ostili alle politiche del Partito comunista, impedendo energicamente ogni tentativo di dissenso ${ }^{31}$.

Nei primi anni del dopoguerra, i processi più importanti e significativi nell'ambito della comunità islamica furono istruiti nei confronti dei Giovani Musulmani (Mladi Muslimani), un movimento religioso affiliato a El-Hidaje, l'associazione degli ulema jugoslavi ${ }^{32}$. Nella primavera del 1946, la stampa di regime descriveva i giovani studenti del movimento come "reazionari", "antidemocratici" e "antipopolari" 33 . I primi provvedimenti giudiziari nei loro confronti risalgono alla fine di marzo dello stesso anno; in quell'occasione furono arrestati e condannati alcuni militanti, tra i quali il futuro primo presidente musulmano della Bosnia-Erzegovina, Alija Izetbegovic $^{34}$. L'ondata di arresti riprese e continuò fino al $1950^{35}$. Nel giro di qualche mese, numerosi processi portarono nelle carceri di Zenica migliaia di esponenti del Movimento ${ }^{36}$. Persino la Comunità religiosa islamica condannò pubblicamente le attività dei Giovani Musulmani attraverso una risoluzione pubblicata su «Oslobođenje» е «Политика» ${ }^{37}$. Sulla vicenda, la

\footnotetext{
29 «Putovanje na Hadž Reis-ul-uleme, zamjenika i drugova», Sa zasjedana Vrhovnog Vakufskog Sabora, 12VII-1950 u Sarajevu, in Glasnik VIS-a, I (XIII), 4-7/1950, p. 152.

30 Устав Федеративне Народне Републике Југославије, глава В, 25, in Службени лист ФНРЈ, II, 10, 1 фебруар 1946, p. 77.

${ }^{31}$ Uprava državni bezbednosti (UDB)

${ }^{32}$ KARIĆ, Enes, Prilozi za povijest islamskog mišlenja u Bosni i Hercegovini XX stoljeća, Vol. 1, Sarajevo, El-Kalem, 2004, pp. 421-458. Il termine "ulema" indica generalemente i depositari della dottrina islamica, i giureconsulti. Si veda VERCELLIN, Giorgio, Istituzioni del mondo musulmano, cit., pp. 239-244.

33 MIDŽić, Dževad, «Povodom pokušaja neprijateljskog djelovanja 'Mladih Muslimana' na nekim srednjim školama u Sarajevu», in Oslobođenje, 5, 31 marzo 1946, p. 13.

34 GREBLE, Emily, Sarajevo la cosmopolita. Musulmani, ebrei e cristiani nell'Europa di Hitler, Milano, Feltrinelli, 2012, p. 259; TRHULJ, Sead, Mladi Muslimani, Zagreb, Globus, Biblioteka posebna izdanja, 1992, p. 13; IZETBEGOVIĆ, Alija, Sjećanja, Sarajevo, Oko, 2005, p. 35. Il caso di El-Hidaje e dei Mladi Muslimani ha favorito approcci contrastanti e antitetici sia in ambito storiografico che nel dibattito politico, in particolare nel corso dei primi anni Novanta. Si veda: KARIĆ, Enes, Prilozi za povijest islamskog mišlenja u Bosni i Hercegovini XX stoljeća, cit., pp. 421-458.

35 FILANDRA, Šačir, Bošnjačka politika u XX stoljeću, Sarajevo, Šejtarija, 1998, pp. 213-214.

${ }_{36}$ JALIMAN, Salih, «Politički osuđenici u kazneno-popravnom domu u Zenici 1945-1954 godina», in Društvena istraživanja, Časopis Pravnog fakulteta Univerziteta u Zenici, II, 2/2008, pp. 13-27.

37 «Resolucija Vakufskog Sabora Islamske Vjerske Zajednice, povodom neprijateljske djelatnosti terorističke organizacije Mladi Muslimani», in Oslobođenje, 877, 16 agosto 1949, p. 2; «Rezolucija Vakufskog Sabora Islamske Vjerske Zajednice povodom neprijateljske djelatnosti terorističke organizacije "Mladi Muslimani", Vakufski sabor IVZ u Narodnoj Republici Bosni i Hercegovini na svom zasijedanju 14. Avgusta 1949. u Sarajevu», in Политика, 13318, 17 VIII 1949, p. 4.
} 
redazione della rivista «Bosanski pogled», organo d'informazione della diaspora bosniacomusulmana, scrisse:

Quando il regime comunista negli anni 1947, 1948 e 1949, arrestò in massa e condannò tutti i rispettabili e onorati funzionari religiosi e arrestò, torturò ferocemente, condannò ai lavori forzati o a morte migliaia di giovani musulmani, proprio allora Ljubunčić con il comunista reis Ibrahim Fejić e altri tre intrapresero il pellegrinaggio alla Mecca con l'obiettivo di dimostrare come tutto ciò dipendesse esclusivamente dalla sola volontà dei musulmani ${ }^{38}$.

Tra il 1945 e il 1955 furono arrestati 319 funzionari religiosi, di cui 154 cattolici, 48 cristianoortodossi, 110 appartenenti alla Comunità religiosa islamica e 7 alle altre organizzazioni religiose minori. Dai primi anni Cinquanta diminuirono gli arresti ma non i provvedimenti disciplinari; dal 1952 al 1955 essi riguardarono 386 religiosi di cui 74 cattolici, 79 ortodossi e 233 musulmani ${ }^{39}$.

Il 13 luglio 1947, in nome di una presunta lotta all' "oscurantismo religioso", il Fronte Antifascista delle donne (Antifašitčki Front Žena) avanzò un'istanza formale al governo per vietare alle musulmane di indossare lo zar e la feredža. Si tratta di un tipo di abbigliamento tradizionale con una profonda valenza simbolico-religiosa, che copre del tutto o in parte il corpo e il volto, all'epoca molto diffuso nella regione anche tra le donne di altre fedi religiose. La proposta fu accolta il mese successivo dal Consiglio Supremo del Vakuf (Vrhovni Vakufski Sabor) ${ }^{40}$. Lo stesso reis Ibrahim Fejić in occasione del suo discorso d'insediamento alla carica di reis-ul-ulema, avvenuto il 12 settembre 1947, espresse il proprio sostegno all'AFŽ, ribadendo sia l'opinione diffusa tra i vertici della Comunità religiosa islamica sia l'indirizzo politico governativo, in quanto considerava quel tipo di abbigliamento un «ostacolo» all'emancipazione femminile ${ }^{41}$. In seguito al fallimento dei numerosi tentativi da parte delle istituzioni civili e religiose di convincere le donne ad abbandonare quel tipo di vestiario, nel settembre del $1950 \mathrm{fu}$ emanata un'apposita legge che vietava l'uso dello zar e della feredža ${ }^{42}$. Le pene per questo tipo di reato prevedevano la sanzione

\footnotetext{
${ }^{38}$ «Ovogodišnji hadžiluk», in Bosanski Pogledi, I, 1/1955, pp.59-60.

${ }^{39}$ Arhiv Bosne i Hercegovine (Archivio della Bosnia-Erzegovina, d'ora in avanti ABH), Komisija Za Vjerska Pitanja (Commissione per gli Affari Religiosi, d'ora in avanti KZVP), Kutija (scatola o faldone) 4, 42/55 «Neka pitanja iz odnosa crkve i države».

${ }^{40}$ ABH AFŽ (Antifašistčki Front Žena), K. 2, Materiali II Konresa AFŽ BiH održanog 12-13 Jula 1947 «Rezolucija Vrhovnog Vakufskog Sabora Islamske Vjerske Zajednice u FNRJ», Sarajevo 26-27 agosto 1947.

${ }^{41}$ «Nastupni govor Reis-ul-uleme Islamske Vjerske Zajednice u FNRJ Ibrahim Fejića, održan prigodom primanja Menšure 12 Septembra 1947 u Gazi husrevbegoj Džamiji u Sarajevu», in Glasnik Vis-a, I (XII), 13/1949, p.23.

${ }^{42}$ «Zakon o zabranji nošenja zar i feredže», in Službeni list NRBiH, VI, 32, 1950, p. 427; Si veda inoltre Glasnik VIS-a, I (XII), 1-3/1950,p. 18; 8-10/1950, pp.278-305, 11-12/1950, pp. 345-347; BEČIROVIĆ, Denis, «Nekoliko napomena o skidanju zara i feredže u Bosni i Hercegovini», in Saznanja, Časopis za Historiju, II, 2008, pp. 184193; MENKOVIĆ, Mirijana M., BAJIĆ, Svetlana, Skriveni svijet Balkanskih žena. Ženska odijeća za ulicu na kraju XIX i u XX vijeku iz zbirki Etnografskog Muzeja u Beogradu i Zemaljskog Muzeja Bosne i Hercegovine u Sarajevu, Sarajevo, Institut za Islamsku tradiciju Bošnjaka, 2014. Questo ultimo testo è corredato da molte
} 
pecuniaria per le donne e l'arresto per coloro che avessero obbligato le donne ad indossare quell'abbigliamento. Nonostante ciò, i musulmani mostrarono una certa resistenza nell'adeguarsi ai nuovi provvedimenti legislativi. Il 7 ottobre 1950, in occasione di una conferenza a Nova Varoš, il vice reis Šećeragić riferì che durante i suoi viaggi in "oriente", in occasione del pellegrinaggio alla Mecca, aveva potuto constatare che le donne musulmane degli stati islamici avevano smesso di indossare lo zar e la feredža, poiché considerati simboli di arretratezza ${ }^{43}$. Un'affermazione sulla cui liceità è opportuno esprimere alcune riserve, specie se si considera che il compagno di viaggio di Šećeragić, Hadži Ljubunčić, a proposito delle donne incontrate alla Mecca, scrisse: «L'ihram delle donne era diverso da quello degli uomini, e tutte le donne, quando indossavano l'ihram, avevano il volto coperto. Quando toglievano l'ihram alcune restavano con il volto coperto. E tra le donne che si erano tolte l'ihram si potevano vedere diversi abiti. E c'erano feredža di diversi colori, e c'erano zar che facevano parte dello stesso vestito» ${ }^{44}$.

Nonostante la piena adesione dei vertici dell'IVZ alle direttive politiche e ideologiche del Partito comunista, le autorità jugoslave continuavano ad esercitare un rigoroso controllo sulle istituzioni religiose islamiche e sui funzionari musulmani. Un fatto noto anche fuori dai confini nazionali, emerso durante la Conferenza islamica mondiale di Karachi (9-11 febbraio 1951) quando i convenuti espressero pubblicamente, attraverso una risoluzione, la loro preoccupazione riguardo gli episodi d'intolleranza religiosa da parte delle autorità jugoslave. Il documento suscitò la formale protesta del reis Ibrahim Fejić, di Hasan Ljubunčić e degli altri esponenti della Comunità religiosa islamica ${ }^{45}$.

Alla fine di marzo del 1952, Mustafa Kaknjo, stagnino di Zenica, inviò una lettera al reis-ululema con la richiesta di intercedere presso le autorità affinché fosse autorizzato a partire per la Mecca assieme ad un gruppo di suoi concittadini. Nonostante il parere favorevole espresso dal Consiglio superiore islamico alla Commissione per gli Affari religiosi, la richiesta non fu accolta. Lo stesso anno giunsero richieste simili anche dalla regione autonoma del Kosovo e dal Montenegro $^{46}$. Nel 1952 e nel 1953, come nei due anni precedenti, nessun aspirante pellegrino fu autorizzato a partire per la Mecca $^{47}$. Il primo pellegrinaggio successivo a quello "istituzionale" del

illustrazioni sui diversi tipi di abbigliamento tradizionale delle donne nella regione balcanica, tra le quali quelle relative allo zar e alla feredža.

43 «Akcija za skidanje feredže u NR Srbiji», in Glasnik Vis-a, I (XII),11-12/1950, p. 347.

44 «Put na Hadž», in Glasnik IVZ, II (XIII), 1-3/1951, p. 54. In questo caso il termine ihram è utilizzato per indicare l'abito rituale che i pellegrini indossano per entrare nel territorio sacro della Mecca.

45 «Povodom rezolucije Svjetske islamske konferencije u Karačiju», in Glasnik VIS-a, II (XIV) 4-6/1951, pp. 107-111; E.R., M.N. "Oriente in Generale», in Oriente Moderno, 31, 4-6/1951, pp. 76-81; «Izvještaj Vrhovno Islamskog starješinstva u FNRJ podnesen Vrhovnom vakufskom saboru 24 novembra 1951 godine. Osvrt na jednu rezoluciju Stalne svjetske islamske konferencije u Karačij-u (Mutemerul Alemil Islam)», in Glasnik IVZ, II, 10-12/1951, p. 435.

${ }^{46}$ ABH KZVP, K. 2, 65/52 «Državna Komisija za Vjerska Pitanja, 4 aprila 1952».

47 È tuttavia opportuno segnalare che in un articolo della rivista "Glasnik», si sostiene che nel 1953 una donna, le cui generalità non sono note, compì il pellegrinaggio alla Mecca.Vedi Glasnik VIS- $a$, XXXIII, 1- 
1949, fu organizzato nel 1954. Il 9 giugno di quell'anno furono accolte le istanze di un gruppo di fedeli tra i quali Muhamed Mujagić, giudice in pensione del tribunale sciaraitico ${ }^{48}$. Il 29 giugno partirono 11 hadžija bosniaci, e per la prima volta una donna, Adila, accompagnata da suo marito Mustafa Hadžiibrahimović. Hasan Ljubunčić fu incaricato nuovamente di accompagnare i fedeli alla Mecca. I pellegrini raggiunsero il porto di Rijeka e si imbarcarono sulla Romanija. La prima tappa fu il porto di Trieste, quindi, dopo alcuni giorni di navigazione, gli hadžija giunsero al porto di Beirut. L'11 luglio la Romanija attraccò al porto egiziano di Alessandria. Dopo alcuni giorni, l'imbarcazione fece rotta per Port Said; qui, attraverso il canale di Suez, i pellegrini raggiunsero Port Sudan. Da quel momento gli hadžija proseguirono con un'altra imbarcazione fino a Gedda, mentre la Romanija riprese la sua rotta commerciale verso Hong Kong ${ }^{49}$.

Dalla metà degli anni Cinquanta, la politica estera jugoslava rivolse i propri interessi diplomatici verso i paesi islamici del vicino e lontano Oriente. Tra la fine di dicembre 1954 e i primi giorni di gennaio Josip Broz visitò l'India, la Birmania e l'Egitto. Al rientro del Presidente in patria, il reis-ul-ulema Ibrahim Feijć affermò di essere «straordinariamente felice» per l'accoglienza riservata a Tito dai rappresentanti del governo egiziano «poiché» - affermò il reis «sono convinto che da questo incontro si avranno risultati vantaggiosi per i popoli di entrambi gli Stati» ${ }^{50}$. E la sua previsione fu giusta, considerando che dal 1955 al 1980, Tito visitò l'Egitto ben diciassette volte ${ }^{51}$.

Nel mese di luglio del 1955 partirono per la Mecca, e per la prima volta in aereo, 65 musulmani jugoslavi; al gruppo dei 54 bosniaci, tra i quali 9 donne, si unirono tre aspiranti hadžija provenienti dalla Serbia e otto dalla Macedonia ${ }^{52}$. Ljubunčić, nella sua duplice veste di pellegrino e funzionario governativo, si apprestava a compiere il suo terzo viaggio alla Mecca come guida della delegazione jugoslava; una prova ulteriore del controllo esercitato dallo Stato sui pellegrini diretti in Arabia Saudita ${ }^{53}$. L'anno successivo il numero dei viaggiatori scese a 31 unità, a causa delle limitazioni imposte dal DSUP.

\footnotetext{
2/1970, p. 2.

48 ABH KZVP, K. 2, (fasc. senza numero) «Sarajevo, 9-6-1954».

49 Glasnik VIS-a, V (XVII), 4-6/1954, pp. 106-107.

50 Glasnik VIS-a, VI, 1-2/1955,p. 4 (vedi inoltre Oslobođenje, 2606, 12 febbraio 1955).

${ }^{51}$ KRSTIĆ, Marija, «Tito kao Turista», in Etnoantropološki problemi, 2/2010, pp. 141-164, p. 143. Sui rapporti tra la Jugoslavia e l'Egitto nel corso della prima metà degli anni Cinquanta si veda ŽIVOTIĆ, Aleksandar, Jugoslavija i Bliski Istok (1945-1956), in Spoljna politika Jugoslavije 1950-1961, Beograd, Institut za Noviju Istoriju Srbije, 2008, pp. 483-496.

52 Glasnik VIS-a, VI, 5-7/1955, p. 189. Quando il viaggio alla Mecca si svolgeva prevalentemente via mare e via terra, e il Zul-hidždže (Dhū l-Hijja) coincideva con i mesi più caldi dell'anno, aumentava il numero dei decessi tra i pellegrini più anziani. Dal 1955 al 1961 morirono 10 hadžija: Hafiz Džemaludin Hadžijahić di Sarajevo nel 1955; Muhamed Goralija, Mustafa Saltagić e Mehmed Dupovac nel 1957; Mahmut Perazić di Ulčinj nel 1958; Mehmed Hafizkadić di Tuzla, Ljuma Rufat di Priština e Mehmed Mustafa di Tetovo nel 1959; Sulejaman Hodžić di Visoko e Mujko Husejnovic di Zivinice nel 1961.

53 NOVAKOVIĆ, Dragan, «Organizacija hadževa i problemi koji su pratili izvršavanje te vjerske obveze u Jugoslaviji od 1945. do 1991. godine», cit., p. 464.
} 
Il $1956 \mathrm{fu}$ un anno molto importante per le relazioni diplomatiche jugoslave. A luglio, Gamāl 'Abd al-Nāṣir Ḥusayn giunse in visita ufficiale a Belgrado, a due anni dalla rivoluzione e dalla nomina a Ministro dell'Interno, e a un mese dalla sua elezione alla Presidenza dell'Egitto. Al suo arrivo in Bosnia, la nutrita delegazione egiziana fu ricevuta dal reis Fejić nella moschea Gazi Husrev-beg, nel cuore della čaršija, a Sarajevo ${ }^{54}$. Il motivo principale della visita del presidente egiziano in Jugoslavia fu l'appuntamento a Brioni, il 18 e 19 luglio, con Tito e il presidente dell'India Jawaharlal Nehru. Dopo la conferenza nella città indonesiana di Bandung (1955), quello di Brioni fu uno degli appuntamenti più importanti per il nascente Movimento dei non allineati. Qualche mese dopo giunse in Jugoslavia il presidente Akmed Sukarno (Kusno Sosrodihardjo); il 14 settembre la delegazione indonesiana fu accolta a Sarajevo dal vice reis-ul-ulema Hadži Murat Šećeragić e dai vertici della Comunità religiosa islamica.

I funzionari dell'IVZ svolsero in quegli anni un importante lavoro di mediazione tra le autorità jugoslave, le delegazioni degli stati arabi e le istituzioni musulmane dei Paesi non allineati. Tito riconobbe pubblicamente il ruolo dei vertici dell'IVZ e il 16 novembre 1956 concesse al reis Fejić un'importante onorificenza per «aver sviluppato e rafforzato la collaborazione pacifica e le relazioni di amicizia tra La Repubblica Federativa Popolare di Jugoslavia e gli altri Stati ${ }^{55}$.

A causa delle continue richieste da parte dei fedeli, il 25 marzo 1957, i funzionari della Comunità religiosa islamica inoltrarono una richiesta alla Commissione per gli Affari religiosi con l'esortazione ad aumentare la quota annuale degli hadžija fino a 50 unità. I funzionari dell'IVZ avevano espresso, infatti, la necessità di stabilire contatti più stabili con i rappresentanti delle istituzioni islamiche di Egitto, Siria e Turchia ${ }^{56}$. L'hadž, da questa prospettiva, avrebbe rappresentato certamente un canale privilegiato per rinsaldare le relazioni con questi e altri Paesi del mondo arabo-islamico. Nonostante le numerose richieste provenienti anche dai singoli cittadini, il numero degli hadžija, per il 1957, rimase vincolato a quota 35. Per la prima volta dal dopoguerra, al gruppo degli hadžija in partenza quell'anno per la Mecca, si unirono Bakalović Hafiz Šukrija, componente del consiglio islamico a Titograd, Montenegro, e il noto giornalista bosniaco Zuko Džumhur. A differenza degli anni precedenti, la maggior parte degli hadžija erano artigiani e contadini; 20 dalla Bosnia, 5 dalla Serbia e 8 dalla Macedonia. Una volta giunti in Egitto, «il 27 giugno i pellegrini furono ricevuti da Gamāl 'Abd al-Nāṣir Ḥusayn su sua iniziativa e in quell'occasione espresse loro la sua stima e il sostegno per la politica jugoslava in particolare per il Presidente Tito» ${ }^{57}$.

\footnotetext{
54 Lo stesso anno, il governo jugoslavo condannò l'aggressione all'Egitto in occasione della crisi di Suez.

${ }^{55}$ Glasnik VIS-a, VII (XIX), 10-12/1956, pp. 293-295.

${ }^{56}$ ABH KZVP, K. 5, 835/57 «Vrhovno Islamsko Starješinstvo Saveznoj Komisiji za verska pitanja, Beograd».

${ }^{57}$ RADIĆ, Radmila, «Islamska Verska Zajednica u službi jugoslovenske spoljne politike», cit., p. 43.
} 
Il 15 novembre 1957, il reis Ibrahim Fejić rassegnò le dimissioni a causa delle precarie condizioni di salute. Il Vrhovni Vakufski Sabor elesse suo successore Sulejman Kemura. La candidatura e l'elezione di Kemura furono sostenute dai funzionari della Commissione per gli Affari religiosi e dalle autorità politiche. La nomina del nuovo reis fu seguita attentamente anche dalla stampa federale. Fu deciso, in quell'occasione, che Radio Beograd avrebbe dovuto annunciare il suo insediamento anche in lingua araba. Si trattò di un evidente gesto di attenzione nei confronti della comunità islamica internazionale ${ }^{58}$.

Con il passare del tempo, nelle dichiarazioni pubbliche dei funzionari religiosi musulmani, la distinzione tra l'ambito religioso e quello politico divenne sempre meno chiara. Nel suo discorso di commiato, trasmesso da Radio Beograd in arabo, alla fine del 1957, il dimissionario reis Ibrahim Fejić sottolineò più volte l'importanza dell'hadž nel favorire l'incontro dei musulmani jugoslavi con il resto del mondo islamico. Gli interventi pubblici del reis dimissionario non si limitarono alle sole questioni di fede. In occasione della crisi di Suez, Fejić ribadì più volte la vicinanza della Jugoslavia all'Egitto condannando pubblicamente l'aggressione del 1956 da parte di Israele, Francia e Inghilterra; ribadì inoltre la piena solidarietà ai movimenti anticolonialisti del Libano, del Sudan, della Tunisia, del Marocco e al movimento indipendentista algerino ${ }^{59}$.

La partecipazione all'hadž, nel corso degli anni Cinquanta, era vincolata essenzialmente alle direttive emesse dalla Segreteria di Stato per gli Affari interni (DSUP); alle decisioni delle autorità diplomatiche saudite preposte al rilascio dei visti d'ingresso nel Paese e, in parte, al non meno trascurabile sforzo economico richiesto agli aspiranti hadžija ${ }^{60}$. Milan Banjac, segretario della Commissione per gli Affari religiosi, in un incontro a Belgrado con il «compagno Bobi» ${ }^{61}$ della Commissione Federale per gli Affari Religiosi (SKZVP), sostenne che l'organizzazione dell'hadž avrebbe dovuto essere delegata esclusivamente alla Comunità religiosa islamica, senza ulteriori ingerenze esterne. Ad ogni modo, rassicurava Banjac «noi resteremo in disparte, ma se dovesse essere necessario inviare alcuni nostri uomini, faremo in modo che questo accada» ${ }^{62}$. Il 10 e il 13

\footnotetext{
${ }^{58}$ ABH KZVP, K. 5, 73/56 «Izbor Reis ul uleme i razgovori vođeni s njim». Il primo numero di Glasnik Vis- $a$ del 1958, su indicazione della Commissione per gli Affari religiosi, fu interamente dedicato all'elezione del nuovo Reis.

59 «Prevod govora koji je održao bivši reis-ul ulema Islamske Vjerske Zajednice u FNRJ Hadži Ibrahim ef. Fejić na radio Beogradu povodom otvaranja stalnih emisija na arapskom jeziku juna 1957. godina», Glasnik VIS- $a$, VIII (XX), 10-12/1957, pp. 389-393.

${ }^{60}$ NOVAKOVIĆ, Dragan, «Organizacija Hadževa i problemi koji su pratili izvršavanje te vjerske obaveze u Jugoslaviji od 1945. do 1991. godine ", in Časopis za suvremenu povijest, 36, 2/2004, pp. 463-471, p. 464; BEČIROVIĆ, Denis, Islamska Zajednica u Bosni i Hercegovini ya vrijeme avnojevske Jugoslavije, cit., pp. 407-408. Le spese di viaggio per i pellegrini, nel 1949, ammontarono complessivamente a 3.485 dollari.

${ }^{61}$ Il "compagno Bobi", ovvero Dobrivoje Radosavljević, personalità di spicco della Lega dei comunisti jugoslavi.

62 ABH KZVP, K. 6, 98/58 «Zabilješka sa sastanka sa pretsjednikom Savezne Komisije za Vjerska Pitanja», 25 maggio 1958.
} 
giugno 1958 partirono in aereo da Belgrado, diretti alla Mecca, 37 hadžija più altri 8 viaggiatori con visto turistico provenienti dalla Macedonia ${ }^{63}$.

Ciò che contraddistinse il mandato del nuovo reis ul ulema Sulejman Kemura, noto con il soprannome «reis rosso», a causa della sua indubbia vicinanza agli ambienti comunisti jugoslavi, furono i frequenti contatti con le delegazioni dei paesi islamici, sia durante i suoi numerosi viaggi all'estero che in occasione dei suoi doveri di ospite in Jugoslavia ${ }^{64}$. All'inizio di quell'anno, Kemura e alcuni funzionari dell'IVZ partirono per un lungo viaggio che li avrebbe condotti prima in Egitto, quindi in Libano, Giordania e Arabia Saudita. Il 21 febbraio giunsero al Cairo; era la vigilia del plebiscito che avrebbe sancito la nascita della Repubblica Araba Unita (UAR), l'unione tra la Siria, l'Egitto e lo Yemen del Nord ${ }^{65}$. La missione diplomatica ebbe i suoi buoni risultati. Il 21 ottobre 1958, giunse in Jugoslavia Šehid Mahmud Šeltut, rettore dell'Università Al Azhar del Cairo. L'anno successivo, il Ministero del Vakuf della Repubblica Araba (UAR) concesse cinque borse di studio a favore degli studenti della medresa Gazi Husrev beg di Sarajevo, senonché il Vrhovno Islamsko Starješintvo non fu autorizzato a inviare i cinque maturandi prescelti, poiché non avevano ancora assolto l'obbligo del servizio militare. Alla fine del 1961, il Ministro del Vakuf dell'UAR rinnovò l'offerta in seguito ad una precisa richiesta da parte del VIS ${ }^{66}$. L'anno successivo, i cinque studenti musulmani raggiunsero l'Egitto per completare gli studi teologici presso la prestigiosa università di Al Azhar; si trattava di Ahmed Smajlović di Tokoljac (Srebrenica), Jusuf Ramić di Šeher (Zvornik), Hamdija Jusufspahić di Zasenović (Bugojno), Merzuk Vejzagić di Guber (Livno) e Salko Čanić di D. Rainac (Tuzla) ${ }^{67}$.

Il 19 maggio 1959, secondo le indicazioni del DSUP, che confermavano essenzialmente la tendenza degli anni precedenti, 36 aspiranti hadžija ottennero il permesso di lasciare la Jugoslavia per l'Arabia Saudita. I complessi aspetti delle relazioni tra la Comunità religiosa islamica e la Lega dei comunisti jugoslavi emergono chiaramente da un rapporto riservato della Commissione per gli Affari Religiosi:

Come è noto, con questa comunità religiosa, almeno con i loro dirigenti, le relazioni sono normali. Chiaro, che in precedenza alcuni nostri organi di ciò ne abusarono[...] e usarono, più di quanto fosse necessario, i componenti dell'IVZ come "propagandisti socialisti" [...] Se a ciò si aggiunge che nel Vakufski Povjerenstvo vi erano una serie di componenti della Lega dei

63 Glasnih VIS-a, VIII (XXI), 9-12/1958, p. 537. Nonostante il limite imposto dalle autorità, nel 1958 otto hadžija riuscirono a ottenere il visto turistico.

64 Kemura s'insediò formalmente il 15 novembre 1957.

${ }^{65}$ Glasnik VIS-a, IX (XXI), 6-8/1958, p. 238. La delegazione era composta da Hafiz Bedri ef. Hamid, presidente dell'Ulema medžlis di Skopljie, Hafiz Bajram ef. Afgani, presidente del Consiglio islamico a Priština, Dževet ef. Palaska, membro del Vrhovno Islamsko Starješinstvo e Hadži Mustafa ef. Ševa, membro dell' Ulema Medžlisa di Sarajevo.

${ }^{66}$ ABH KZVP, K. 13, «Iz informacije IVZ».

${ }^{67}$ Glasnik VIS-a, XIII (XXV), 10-12/1962, p. 335. 
comunisti jugoslavi, e persino i componenti dei comitati distrettuali, allora, almeno fino a un certo punto, diventa chiaro poiché alcuni elementi della Comunità religiosa islamica sono stati definiti agitatori comunisti e liquidatori dell'islam [...] Negli ultimi due anni abbiamo rimediato agli errori. Dal Povjerenstvo abbiamo eliminato le persone compromesse e scelto persone con una buona disposizione patriottica, che si sentono jugoslavi [...] Ravvisando una tale situazione abbiamo avanzato la questione della scelta e dell'elezione del reis-ul-ulema. Abbiamo previsto il candidato Kemura Hadži Sulejman, attuale direttore della medresa. Per quasi due anni abbiamo lavorato per la sua affermazione (disbrigo dell'hadž, partecipazione alla pubblicazione di testi religiosi [...] le visite nelle altre repubbliche, l'invio degli alunni delle medrese in diverse regioni del nostro Paese in occasione del Ramadan... ${ }^{68}$.

I successi della diplomazia jugoslava furono coronati dai frequenti contatti che a partire dal 1959 si stabilirono tra il Vrhovno Islamsko Starješinstvo e le istituzioni religiose dei paesi arabi di tradizione islamica $^{69}$. Il 16 dicembre giunse in Bosnia Hikmet Hašim, rettore dell'Università di Damasco; il 20 gennaio fu la volta di Muhamed El-Arebi, aiuto Ministro degli Affari Esteri del governo provvisorio algerino, e l'11 aprile 1960, Hasan Zumuri, sottosegretario del Ministero degli Affari interni del Marocco ${ }^{70}$. Tra aprile e maggio, Kemura accolse «un gruppo di turisti francesi, l'ambasciatore indiano a Belgrado, una delegazione irachena e una delegazione parlamentare tunisina; stabilì, inoltre, contatti con quasi tutti i rappresentanti religiosi di Africa e Asia». Bisognava in tutti i modi spazzare via la propaganda che i "nemici del popolo" avevano diffuso nei Paesi arabi riguardo il «mancato rispetto per la libertà religiosa in Jugoslavia» ${ }^{71}$ Il 10 luglio, il reis Kemura e il suo capo gabinetto Abdurahman Hukić partirono per Baghdad su invito del nuovo governo iracheno per assistere alle celebrazioni in onore della rivoluzione avvenuta due anni prima.

Nel 1960 partirono per la Mecca 37 musulmani jugoslavi. Al gruppo si unì, per la prima volta dal dopoguerra, un musulmano proveniente dalla Croazia ${ }^{72}$. A distanza di anni dal pellegrinaggio del 1949, le autorità jugoslave continuavano a esercitare un rigido controllo sulle richieste di espatrio per motivi religiosi. «Todor Kurtović, presidente della Commissione per gli Affari religiosi per la Bosnia-Erzegovina è stato per 7 anni ufficiale dell'UDB [...]. Egli esamina le

\footnotetext{
${ }^{68}$ ABH KZVP, K. 7, 126/59 «Podaci sa naredno savjetovanje u Saveznoj komisiji za vjerska pitanja».

69 Il "Vrhovno Islamsko Starješinstvo", letteralmente "Consiglio superiore islamico".

70 ABH KZVP, K. 10, 210/60 «Posjete delegacije i ličnosti iz inostranstva učinjenih Reis ul ulemi u aprilu i maju ove godine». I nomi dei politici in questione sono riportati nella trascrizione serbo-croata, come nell'originale sui documenti.

${ }^{71}$ RADIĆ, Radmila, «Islamska Verska Zajednica 1945-1970. godine», cit., p. 112.

72 Archivio Gazi Husrev Beg, fascicolo «Hadžiluk», V 12, 2828/60, 1093/60, 12 aprile 1960. Il numero dei fedeli autorizzati a partire per la Mecca differiva secondo la repubblica di provenienza.
} 
prenotazioni per l'hadž e personalmente sulla base delle informazioni dell'UDB, autorizza o nega la partenza per la Mecca. Quest'anno su 174 candidati sono stati autorizzati solo in $35 »^{73}$.

Gli anni Sessanta si aprirono con importanti novità nelle relazioni tra il Partito comunista jugoslavo e la componente musulmana bosniaca. Uno dei segni tangibili dell'attenzione riservata ai musulmani si manifestò in occasione del censimento del 31 marzo 1961. Rispetto alle precedenti rilevazioni del 1948 e del 1953, quando lo status giuridico e amministrativo dei musulmani si riferiva esclusivamente alla loro identità religiosa, nel 1961 fu introdotta la categoria censitaria "Musulmani in senso etnico" (Muslimani u etničkom smislu). Si trattava di un primo importante riconoscimento, da parte delle autorità, dell'esistenza di un'identità musulmana che andava oltre i limiti dell'appartenenza religiosa; era l'inizio di un processo politico che si sarebbe concluso nel 1974 con la piena affermazione dei musulmani come nazione costituente ${ }^{74}$. La questione musulmana, nel corso della prima metà degli anni Sessanta, si inseriva nel più ampio dibattito politico e istituzionale riguardo le relazioni tra i gruppi nazionali jugoslavi che trovò una sua prima formulazione in occasione dell'VIII congresso della Lega dei comunisti jugoslavi (7-13 dicembre 1964, Belgrado) ${ }^{75}$.

Le novità più importanti riguardo il numero dei partecipanti ammessi all'hadž giunsero proprio nel 1961. All'inizio dell'anno, in occasione dell'importante summit internazionale di Belgrado, previsto per la prima settimana di settembre, i funzionari della Lega dei comunisti si preparavano ad accogliere le delegazioni di 25 Paesi del Movimento dei non allineati, tra cui i rappresentanti dell'Egitto e dell'Arabia Saudita.

La novità più rilevante di quell'anno fu la rimozione del limite massimo degli aspiranti hadžija. Il primo marzo 1961, infatti, i funzionari del Vrhovno Islamsko Starješinstvo comunicarono ufficialmente la notizia ai loro omologhi della Repubblica Popolare di Macedonia ${ }^{76}$. Da quel momento in poi, le istanze d'espatrio per il pellegrinaggio alla Mecca, in assenza di particolari impedimenti, sarebbero state tutte autorizzate indipendentemente dal numero delle richieste.

Il 4 aprile 1961, in occasione del Bajram, il Reis Kemura rivolse i saluti della comunità islamica jugoslava a tutti i musulmani del mondo arabo. Nel messaggio del Reis, trasmesso da Radio Beograd, fu più volte sottolineata la necessità di sviluppare maggiormente le relazioni tra le

\footnotetext{
73 «Islamska Zajednica u borbi za opstanak. Metode Komunističkih vlasti protiv Muslimana», in Bosanski Pogledi, I, 3, 1960, in Bosanski Pogledi, Nezavisni list Muslimana Bosne i Hercegovine u iseljeništvu, 1960-1967, London, Pretisak, 1984, p.41. Nel numero degli hadžija indicato nell'articolo in questione, probabilmente non furono conteggiate le guide, la cui autorizzazione non seguiva, probabilmente, lo stesso iter burocratico degli altri pellegrini.

74 Popis Stanovništva, Knjiga VI. Vitalna, etnička i migraciona obeležja, Socijalistička Federativna Republika Jugoslavija, Beograd, Savezni Zavod za statistiku, 1967, pp. XIX-XX; Nacionalni sastav stanovništva SFR Jugoslavie, podaci po naseljima i opštinama, Beograd, Savezni zavod za statistiku, 1991.

75 RAMET, Sabrina P., The Three Yugoslavias. State-Building and Legitimation, 1918-2005, Bloomington and Indianapolis, Indiana University Press, 2006, p. 210.

${ }^{76}$ Glasnik VIS-a, XIII (XXV), 1-3/1962, p. 54.
} 
istituzioni islamiche jugoslave e quelle dei Paesi arabi ${ }^{77}$. Quell'anno, tra il 30 aprile e il $1^{\circ}$ maggio 1961 partirono dall'aeroporto di Belgrado 154 hadžija, 72 dei quali provenivano dalla BosniaErzegovina. Alla guida del gruppo fu designato Mustafa Ševa, direttore della medresa di Sarajevo; una scelta non condivisa da tutti, in particolare dall'autore della lettera anonima che qualche mese dopo fu recapitata al reis Kemura.

Quanto questo fatto del pellegrinaggio, sebbene in sostanza un rito religioso, sia legato in maniera molteplice alle nostre attuali vicende socio-politiche, Voi indubbiamente non lo considerate nel giusto modo. Quanto sia poi il pellegrinaggio attraente come cerimonia religiosa per i più ampi circoli dell'IVZ dell'intero Stato, a Voi è eccezionalmente noto. [...] $\mathrm{E}$ nonostante queste trasgressioni del 1961, trasgressioni nel cerimoniale del pellegrinaggio, riguardo l'eccezionale numero di pellegrini, e altri aspetti, avete affidato personalmente la guida del viaggio a Mustafa efendija Ševa, tuttora direttore della medresa, sebbene foste personalmente convinti, che il succitato non avesse nessuna qualifica per questo compito ${ }^{78}$.

Ševa, in quanto cognato del reis Kemura, avendo sposato sua sorella, godeva di numerosi privilegi presso la massima autorità della Comunità religiosa islamica. Non si trattava certamente di un caso isolato. Il reis Kemura, in più di un'occasione, aveva chiaramente favorito l'assunzione dei propri familiari nelle istituzioni della Comunità religiosa islamica con il silenzio imbarazzante dei quadri comunisti ${ }^{79}$.

Nel 1961, Midhat Husejnefendić, un tassista di Tuzla, partì in automobile per la Mecca assieme ad altri tre concittadini ${ }^{80}$. Il viaggio fu organizzato e realizzato in totale autonomia, ovvero senza la mediazione delle istituzioni religiose islamiche. I 4 hadžija raggiunsero l'Arabia Saudita attraversando la Bulgaria, la Turchia, la Siria e la Giordania; il viaggio durò quasi due mesi. Midhat avrebbe ripetuto l'esperienza anche negli anni successivi. Il pellegrinaggio di Midhat e dei suoi compagni sanciva simbolicamente l'inizio di una nuova fase dei rapporti tra il Partito comunista, la comunità religiosa islamica e i fedeli musulmani. Nel corso degli anni successivi, l'hadž registrò un alto numero di presenze, seppur contenute rispetto alla popolazione

\footnotetext{
77 ABH KZVP, K. 13, 197/61, «Bajramska poslanica Reis ul uleme upučena muslimanima u Arapskim zemljama povodom bajrama 1961».

${ }^{78}$ ABH KZVP, K. 13, 197/61 «Reisul ulemi, uvaženom Sulejman eff. Kemuri, 5 Jula 1961».

${ }^{79}$ ABH KZVP, K. 25, 283 «Materijal sastanka u vezi IVZ 8/XI/1963». «Così negli organi dell'IVZ si trovano: il direttore della Medresa, Ševa Mustafa, marito della sorella; il figlio nell'organo di controllo edile del Povjerenstvo; il cugino, dirigente nel Povjerenstvo, la figlia, nella Medresa insegna storia dell'islam, sebbene non abbia la qualifica; la cugina, insegnate nella Medresa, un'altra cugina, che vive a Mostar, revisore dei testi a «Glasnik»; il figlio del fratello impiegato in biblioteca; un'altra cugina impiegata nel Vrhovni Islamski Starješinstvo».

${ }^{80}$ URL: < https://www.preporod.com/index.php/sve-vijesti/drustvo/item/7974-prvi-hadzija-iz-jugoslavijekoji-je-automobilom-otisao-na-hadz > 8 Septembar 2017 [consultato il 14 ottobre 2018].
} 
complessiva di fede islamica, diventando uno degli eventi religiosi ricorrenti più importanti per gran parte della comunità islamica jugoslava ${ }^{81}$.

\section{Conclusioni}

A partire dalla seconda metà degli anni Cinquanta, la nuova fase della politica estera jugoslava, sempre più orientata verso i paesi non allineati, coincise con il mutato atteggiamento delle istituzioni nei confronti della componente musulmana. Non si trattava certamente di relazioni esclusive. Le autorità jugoslave, negli stessi anni, intrattenevano importanti relazioni diplomatiche con gli Stati Uniti, ma interruppero, ad esempio, quelle con la Santa Sede, dal 1952 al $1963^{82}$. I fattori che incisero sull'orientamento diplomatico jugoslavo, durante la crisi con l'Unione Sovietica, e nel corso degli anni Sessanta, furono diversi e molto complessi. In parte essi erano riconducibili all'emergenza economica e al tentativo (fallimentare) del modello di autogestione operaia (radničko samoupravljanje); alle tensioni tra le tendenze a favore del decentramento e le resistenze da parte di coloro (conservatori) che erano favorevoli al centralismo del potere politico e delle funzioni amministrative; al tentativo di stabilire rapporti di uguaglianza tra i popoli e le repubbliche jugoslave (ravnopravnost); alla volontà di riformulare un proprio approccio al socialismo basato sulla lotta al burocratismo, e non ultimo, alla continua necessità di riorganizzare la difesa militare dei confini, specialmente durante le crisi che in più occasioni minacciarono la stabilità della regione (la crisi russo-jugoslava del 1948, in Ungheria nel 1956, in Polonia e in Cecoslovacchia nel 1968).

La mediazione dell'IVZ nei rapporti con i Paesi islamici non-allineati si rivelò preziosa sotto molti punti di vista. L'hadž fu innanzitutto un fenomeno religioso, le cui implicazioni negli Affari interni e nelle attività di politica estera non possono essere licenziate come effetti accidentali dei rapporti diplomatici; lo dimostrano le dichiarazioni del Consiglio Esecutivo Federale: «la politica del non allineamento è di importanza capitale per la nostra sicurezza nazionale e in essa si trova l'essenza della nostra politica d'indipendenza» ${ }^{83}$. L'hadž fu quindi uno dei canali privilegiati, accanto a quello degli scambi economici, per rinsaldare le relazioni diplomatiche con i Paesi arabi, attraverso la mediazione dei funzionari religiosi islamici. Il nuovo orientamento della diplomazia

\footnotetext{
${ }^{81}$ Tra il 18 e il 20 aprile 1962 partirono 140 Hadžija. Esattamente dieci anni dopo, partirono 2.732 viaggiatori; un numero che comprendeva anche gli hadžija che si organizzarono in modo autonomo, ovvero fuori dal contesto dell'IVZ. Si veda a proposito l'articolo di ĐOZO, Husein, Islam. Hadž, in Glasnik VIS-a, XXXV, 3-4/1972, p. 114.

82 ŽUTIĆ, Nikola, «Protokol Jugoslavije i Vatikana iz 1966. Godine», in Istorija 20. Veka, 1/2013, pp. 135-156; AKMADŽA, Miroslav, «Pregovori Svete Stolice i Jugoslavije i potpisivanje protokola iz 1966. godine», in Časopis za suvremenu povijest, 36, 2/2004, pp. 473-503.

83 ABH, Izvršno Vijeće BiH (Consiglio Esecutivo della Bosnia-Erzegovina), K. “75-107”, 1968, 106/1968 «Pregled zadataka Saveznog Izvrsnog Vijeća za 1969 godinu, Beograd 18 decembra 1968. godine».
} 
jugoslava, dopo l'espulsione del KPJ dal Cominform, ebbe importanti e inevitabili ripercussioni nei rapporti tra lo Stato e la componente musulmana. Il fenomeno dell'hadž, nella sua dimensione sociale, è uno degli indicatori attraverso i quali è possibile seguire l'evoluzione di tali rapporti. Verso la fine degli anni Cinquanta, alcuni elementi confermerebbero una certa distensione tra $\mathrm{i}$ vertici politici e i funzionari religiosi musulmani che culminerà, nei primi anni Settanta, in una definitiva, seppur discutibile, soluzione della questione nazionale bosniaca con il riconoscimento della componente musulmana quale entità nazionale costituente ${ }^{84}$. La posizione delle autorità nei confronti di uno dei più importanti aspetti della religione islamica, nel periodo in esame, fu a tratti controversa. Il regime, che ostentava a tutti i costi il suo atteggiamento di dubbia tolleranza nei confronti dei funzionari religiosi, in sostanza non allentò mai il suo serrato controllo sulle attività delle istituzioni religiose e sui credenti. La limitazione e la selezione degli aspiranti hadžija, secondo le direttive degli Affari Interni e la partecipazione più o meno occulta dei funzionari del Partito al pellegrinaggio, confermerebbero tali ipotesi. Le dichiarazioni di Moskovljević dal Cairo, di Lilić da Damasco, del segretario della Commissione per gli Affari religiosi Milan Banjac, la reiterata presenza di Ljubunčić, e poi di Ševa, tra i pellegrini diretti alla Mecca, attestano una forte ingerenza da parte dello Stato in uno spazio tradizionalmente riservato alla dimensione religiosa individuale e collettiva, almeno fino al 1961. A partire da quell'anno in poi, i musulmani jugoslavi avrebbero riconquistato, poco alla volta, uno spazio "sacro" dal quale le autorità politiche e governative sarebbero state in parte escluse.

\footnotetext{
84 La questione nazionale e in generale i fenomeni di nazionalismo, nel dibattito politico federale, furono affrontati sistematicamente a partire dall'VIII Congresso della Lega dei comunisti jugoslavi (Belgrado, 7-13 dicembre 1964). Il primo di una serie di atti del percorso istituzionale che si concluse con il riconoscimento formale della componente musulmana quale sesta nazione costituente della SFRJ, furono le dichiarazioni emerse durante la XVII e la XX seduta del Comitato Centrale della Lega dei comunisti di Bosnia-Erzegovina (CKSKBiH, gennaio e maggio 1968). In entrambe le occasioni fu più volte ribadito che i musulmani rappresentavano un "popolo distinto" rispetto alle altre componenti nazionali jugoslave. Si trattava ancora di dichiarazioni formali, seppur molto importanti in quanto si affermava, per la prima volta in un contesto politico-istituzionale, l'esistenza di un'entità nazionale musulmana. Un passo decisivo fu compiuto nel 1971, in occasione del censimento della popolazione, quando fu adottata la categoria "Musulmani in senso nazionale" (Muslimani u nacionalnom smislu). Si trattò, in sostanza, del passaggio più importante del processo di affermazione nazionale della componente musulmana della Bosnia-Erzegovina. La "nascita" della nazione musulmana fu infine legittimata nell'ambito della Costituzione della SFRJ e della SRBiH, entrambe del 1974. (Per approfondire l'argomento, si rimanda alla bibliografia indicata nella nota 3 del presente saggio).
} 


\section{L'AUTORE}

Mario Giulio SALZANO, è dottorando in Storia dell'Europa dal Medioevo all'età contemporanea "Università degli Studi di Teramo" presso l'Università degli Studi di Teramo. Tema della sua ricerca è: La questione nazionale bosniaco-musulmana (1949-1971).

URL: < http://www.studistorici.com/progett/autori/\#Salzano > 